\title{
New year, new look, new content
}

Kong Med J 2014:20:4

Ignatius TS Yu, FHKAM (Community Medicine)

Editor-in Chief, Hong Kong Medical Journal

DOI: 10.12809/hkmj131402

As we step into the new year of 2014, the Hong Kong Medical Journal (HKMJ) is having a new look. The previous design was used for seven years and the Editorial Board believed that the journal warranted a new dress in this new year.

We spent a lot of time designing the new journal cover that you have received in this issue. It incorporates a modern and clean design; more white space is created, which breaks things up a little, making it easier on the eye. This lets our cover 'breathe', which is exactly what we wanted to achieve-to let our readers enjoy reading the journal in an uncluttered and relaxed way. A skyline of Hong Kong harbour, which is considered one of the best in the world, illustrates our pride for the city. A trimmed version of the Table of Contents is retained on this new cover to provide a quick overview of what is inside in the issue, which is perfect for busy doctors. There is also an 'interior re-design' starting this issue. The font of the text has been changed to a serif one to enhance readability. The abstract page has also been re-organised to better use the space.

Now with the fresher look, the HKMJ is also offering a new section-Reminiscence: Artefacts from the Hong Kong Museum of Medical Sciences. This is a collaborative effort with the Hong Kong Museum of Medical Sciences. Each article will consist of photo(s) of artefact(s) held by the Museum together with a short description on the related background or history.

I hope readers will enjoy our new cover and layout, and also the new section. 